\title{
Molecular Basis of Flower Formation in Apple Caused by Defoliation and Gibberellins
}

\author{
Mokhles A. Elsysy \\ Department of Horticulture and Landscape Architecture, Purdue University, 625 Agriculture Mall \\ Drive, West Lafayette, IN 47907; and Department of Pomology, College of Agriculture, Assiut \\ University, Assiut 71515, Egypt \\ Peter M. Hirst \\ Department of Horticulture and Landscape Architecture, Purdue University, 625 Agriculture Mall \\ Drive, West Lafayette, IN 47907
}

\begin{abstract}
AdDitional INDEX words. alternate bearing, biennial bearing, Malus $\times$ domestica, MdFT1, MdTFL1, return bloom
Abstract. Adequate flower formation limits dependable apple (Malus $\times$ domestica) production and is a major challenge for apple industries around the world. 'Honeycrisp' is a high value apple cultivar, but consistent flowering is difficult to achieve. Apple flower formation is affected by factors including defoliation, girdling, and gibberellin $\left(\mathbf{G A}_{4+7}\right)$ and 1-naphthaleneacetic acid (NAA) applications. However, the molecular mechanisms that regulate the effects of these factors are not well understood. We studied the effect of local spur defoliation, GA $\mathrm{G}_{4+7}$ and NAA applications on 'Honeycrisp' flower formation. Furthermore, we investigated the effect of local defoliation and local $\mathbf{G A}_{4+7}$ application on the transcript levels of two major flower formation genes in the meristems of apple spurs. The floral inhibition gene terminal flower1-1 (MdTFL1-1) and floral promoting genes flowering locus T (MdFT1 and MdFT 2) of apple. Local application of $\mathrm{GA}_{4+7}$ and defoliation treatments inhibited flower formation, but NAA applications were without effect. Defoliation treatments were accompanied by a significant reduction in MdFT1, 2 transcript levels compared with controls early in the growing season. Conversely, $\mathbf{G A}_{4+7}$ application was accompanied by a significant increase in MdTFL1-1 transcripts compared with controls throughout the growing season. These results indicate that $\mathbf{G A}_{4+7}$ inhibits flower formation by upregulating the inhibitory MdTFL1-1, and defoliation acts by downregulating transcript levels of MdFT1, 2 early in the growing season. We also provide evidence that defoliated bourse buds may receive flowering promotion signals from other parts of the tree in the absence of their local leaves.
\end{abstract}

Flowering is a key developmental stage of apple biology and one of the primary aspects that affects apple production. Flower formation results from the complex interaction of endogenous pathways and environmental conditions. Many apple fruit production problems are associated with flower formation, the most commercially important being biennial bearing, which is "the fluctuation in cropping from year-to-year caused by irregular flowering" (Hirst, 2017). 'Honeycrisp' is a newer apple cultivar that is popular with consumers but has a severe tendency for biennial bearing. Therefore, the elucidation of the molecular mechanisms that regulate flower formation is not only important for the commercial production of 'Honeycrisp' apples but also makes this cultivar a good model for studying these mechanisms.

Plant growth regulators have been implicated to play a major role in controlling flower initiation and biennial bearing in apple. Exogenous application of gibberellins (GAs) soon after full bloom can promote vegetative growth and inhibit flower formation (Bangerth, 2009; Marino and Greene, 1981; McArtney and Li, 1998; McLaughlin and Greene, 1984). The identification of GA activity in apple seeds during the early stages of

Received for publication 6 June 2019. Accepted for publication 28 Aug. 2019. We thank Bruce Craig and Rongrong Zhang from the Purdue statistical consulting service for their advice on statistical design and analysis. We also thank Michael Mickelbart, Avtar Handa, Mostafa Abushahba, Aziz Ebrahimi, Tatsiana Datsenka, and Mike Gosney for their assistance with this research. M.A.E. thanks lab mates Andres Mayorga, Khalil Jahed, Jacob Franzen, Biying Shi, Fatemeh Sheibani, Seval Taskin, and Bofan Xie for their help during different phases of this experiment.

P.M.H. is the corresponding author. E-mail: hirst@purdue.edu fruit development (Dennis and Nitsch, 1966) led to the assumption that seed-derived GAs inhibit flower formation in apple (Chan and Cain, 1967). Dennis and Neilsen (1999) suggested that the inhibitory effect of GAs from the seeds on flower formation is not ultimate and that further research may implicate GAs, auxins, or both as important regulators for biennial bearing. Mapping a quantitative trait locus in the genome of apple associated with biennial bearing showed four main genomic regions containing floral genes, gibberellin oxidase genes, and meristem identity genes (Guitton et al., 2012). This finding supported the hypothesis that GAs influence flower formation, and further research on the interaction between growth regulators and molecular floral initiation pathways will likely increase our understanding of apple flowering and biennial bearing.

Leaves are the main source of flower formation signals (Hanke et al., 2007). Not only are they the main receptor for environmental signals but they also produce carbohydrates and plant growth regulators. Recently, we showed that flowering did not appear to be related to factors associated with spur carbohydrate status, suggesting a direct role of genes regulating flowering and plant growth regulators (Elsysy et al., 2019). Flower induction genes have been shown to be active in the leaves (Hanke et al., 2007). Flower formation is affected by leaf area (Sahulka, 1967), and defoliation decreased flower formation (Elsysy and Hirst, 2017; Fulford, 1960; Harley et al., 1942). Flower formation was inhibited with partial and whole tree defoliation in 'Braeburn', 'Golden Delicious', 'Ramey York', and 'Fuji' (Davis, 2002). There is a clear relationship between flower formation and defoliation time and severity, as flower 
formation increases as defoliation time was delayed (Davis, 1957; Liewelyn, 1968), and as defoliation severity was reduced (Harley et al., 1942; Tustin et al., 1997). In addition to leaf area, the types of leaves are also important for flower formation. Our recent work showed that bourse leaves, but not spur leaves, were important in the regulation of flower formation in apple (Elsysy and Hirst, 2017). Moreover, the effect of local inhibitions such as fruiting and defoliation could be affected by the availability of flowering promotion signals in the whole tree (Elsysy and Hirst, 2017).

In fruit-bearing shoots, flower formation is affected by several environmental and internal cues. For example, sugar, temperature, and daylength are positive effectors, whereas GAs are well-known negative regulators (Mimida et al., 2013). Bioactive GAs may play a role in the control of key flowering genes in apple (Guitton et al., 2016). The crosstalk between sugars and plant growth regulators mediates bud development and flower formation in apple (Xing et al., 2015). Flowering locus $T$ (MdFT1), apetala1 (MdAP1), and the apple ortholog of leafy $(M d A F L)$ are flowering promoters, but terminal flower1 (MdTFL1) is a flowering repressor (Mimida et al., 2013; Xing et al., 2015). Two flowering regulator gene families, FT and $T F L$, have been characterized and isolated in various plant species, with $F T$ generally promoting flowering and $T F L$ inhibiting flowering (Hanke et al., 2007). In addition, homologs of these two genes have been characterized in several fruit species, including apple (Kotoda and Wada, 2005; Kotoda et al., 2006; Mimida et al., 2013), japanese pear (Pyrus pyrifolia), european pear (Pyrus communis), quince (Cydonia oblonga), chinese quince (Chaenomeles sinensis), loquat (Eriobotrya japonica) (Esumi et al., 2005), and sweet orange [Citrus sinensis (Pillitteri et al., 2004)]. It has been well established in apple that MdFT1 is the main flower formation promoter (Kotoda et al., 2010; Mimida et al., 2011), and MdTFL1 is a major flower repressor (Flachowsky et al., 2012; Kotoda et al., 2006).

Over the last 10 years, much of the research to explain the molecular mechanisms of flower formation in apple has focused on two main genes, MdTFL1 and MdFT1. Several transgenic apples with antisense MdTFL1 RNA transgene flower very early compared with control plants (Kotoda et al., 2006). In addition, MdTFL1 plays an important role in the vegetative growth of apple, and silencing this gene is a critical step toward forming the flowering bud in apple (Flachowsky et al., 2012; Kotoda et al., 2006). Exogenous application of gibberellins led to a significant increase in the MdTFL1 transcript level in apple (Haberman et al., 2016).

Two flowering genes of apple, MdFT1 and MdFT2, induced early flower formation in transgenic Arabidopsis thaliana (Kotoda et al., 2010). The transcript levels of MdFT1 were higher in meristematic buds, but MdFT2 showed higher transcript levels in the reproductive organs (Kotoda et al., 2010). MdTFL1 transcripts were identified in the meristem of apple buds before budbreak (Hättasch et al., 2009; Mimida et al., 2011). In early summer during the time of flower initiation, MdTFL1 is barely detectable and MdFT1 and some other flowering genes are upregulated (Hättasch et al., 2009; Mimida et al., 2011).

We hypothesize that local flower formation regulators affect the expression patterns of flower promotion and inhibition genes. The objective of our study was to determine the local effects of gibberellins, auxins (NAA), and defoliation on flower formation in 'Honeycrisp' apple and to investigate the relationships between flower formation and expression patterns and levels of MdTFL1-1 and MdFT1, 2 in meristematic buds.

\section{Methods}

\section{Plant material}

Mature 'Honeycrisp' trees planted in 2003 and growing on 'M.7 EMLA' (M.7) rootstock were used for the present investigation. Trees were planted at a spacing of $3 \times 5 \mathrm{~m}$, trained to a vertical axis form, and managed according to standard commercial practices. The orchard was located at the Samuel G. Meigs Horticulture Facility of Purdue University, Lafayette, IN. Crop load was adjusted manually by hand thinning at petal fall to achieve light crop loads of 60-80 fruit per tree. In 2012, the year preceding the experiment, a series of severe spring frosts resulted in almost total fruit loss, which provided a uniformly low previous crop load for all trees.

\section{Experimental procedure}

The experiment was arranged as a randomized complete block design, with 24 trees arranged in six blocks, with four trees per block, treated as a single experimental unit. The experiment was conducted over two consecutive seasons, Spring 2013 and 2014, on the same set of trees.

Treatments. Two hundred flowering spurs were randomly selected in each block (across four trees), tagged using durable plastic tags, and flowers were removed before petal fall. Tagged spurs were at least $20 \mathrm{~cm}$ apart from each other to avoid possible interactions among different treatments. Each treatment was randomly assigned to 50 spurs across the four trees in each block according to the tag color. Treatments were a) control, b) defoliation, c) exogenous application of $400 \mathrm{mg} \cdot \mathrm{L}^{-1}$ $\mathrm{GA}_{4+7}$ (Provide; Valent Biosciences, Libertyville, IL), and d) exogenous application of $0.147 \mathrm{~mL} \cdot \mathrm{L}^{-1} \mathrm{NAA}$ (Fruitone $\mathrm{N}$; AMVAC Chemical Corp., Newport Beach, CA). Both $\mathrm{GA}_{4+7}$ and NAA treatments were applied using small spray bottles to target the application only to specific spurs assigned to these treatments. Defoliation treatments were reapplied on the same spurs 2 weeks and 1 month after the start of the experiment because after defoliation, new leaves emerged on the spurs as bourses continued to grow. Treatments were applied at a time that previous studies indicated to be most effective in manipulating flowering. Defoliation was applied at petal fall (Davis, 1957; Liewelyn, 1968), GA $4+7$ was applied 2 weeks after full bloom (Marino and Greene, 1981; McArtney and Li, 1998; McLaughlin and Greene, 1984) and NAA was applied four times to the same spurs $55,65,75$, and $85 \mathrm{~d}$ after full bloom (McArtney et al., 2007). Full bloom occurred on 3 May 2013 and 10 May 2014.

Plant material and sample collection. Ten bourse buds were collected from each treatment and each block, and in each sample date, they were immediately immersed in liquid nitrogen then stored in a $-80^{\circ} \mathrm{C}$ freezer for later RNA extraction. Bourse bud samples were collected on three sample dates, $\approx 25,45$, and $65 \mathrm{~d}$ after full bloom (DAFB) for control, defoliation, and $\mathrm{GA}_{4+7}$ treatments. However, for NAA treatment, bourse buds were collected on 55, 65, and 85 DAFB. During winter, while trees were dormant, 20 tagged spurs were collected from each treatment in each block, and bourse buds were dissected under a dissecting microscope (Olympus Corp., Center Valley, PA) to determine flower formation (Hirst and Ferree, 1995). 
R NA EXTRACTION AND QUANTIFICATION. On each sampling date, buds of each treatment in each block were pooled into one sample. Analysis of transcript levels was conducted on three blocks with three technical replications for each block. NAA treatment did not show significant effects on flower formation in either year of the study; therefore, transcript levels for these treatments were not analyzed. Total RNA was extracted from bud samples as previously described (Japelaghi et al., 2011), and cDNA was synthesized as described by Shalom et al. (2012). Primers for the genes encoding for Flowering locus T, MdFT1 (MDP0000132050) and MdFT2 (MDP0000139278), and Terminal flower MdTFL1-1 (MDP0000255437) were designed using Primer 3 software (Untergasser et al., 2012) (Table 1). Real-time PCR was then carried out on a CFX96 Real-Time PCR Detection System (Bio-Rad Laboratories, Hercules, CA), with PerfeCTa SYBR Green FastMix (Quantabio, Beverly, MA) in a $15-\mu \mathrm{L}$ final volume to determine the transcript levels of the target genes. The ubiquitin $\mathrm{C}(U B C)$ gene (MDP0000205182) was used as an internal control for the normalization of gene transcript levels (Storch et al., 2015).

\section{Statistical analysis}

Flower Formation. Data were analyzed using flower formation as the response factor. Treatments were compared within each year separately. Data are presented as percentage of flower formation for each treatment in each year. Analysis was conducted using binomial logistic regression with mixed effects, with all treatments compared with control $(P<0.05)$, using the statistical package $\mathrm{R}$ (version 3.2.2; R Foundation, Vienna, Austria).

Gene TRANSCRIPT LEVELS. Real-time quantitative reverse transcriptase PCR results were analyzed using the $2 \Delta \Delta \mathrm{C}(\mathrm{T})$ method (Livak and Schmittgen, 2001). Comparisons were performed among treatments within dates. Statistical significance was determined using the two-tailed Student's $t$ test $(P \leq$ $0.05)$. Data are presented as a fold change in the transcript level. Analyses were also conducted using R.

\section{Results}

EFFECT OF TREATMENTS ON FLOWER FORMATION. Flower formation of control spurs was variable between the 2 years of investigation, indicating a high degree of biennial bearing among the trees used for this study. Controls in 2013 exhibited $71 \%$ flower formation compared with $11 \%$ in 2014 (Fig. 1). Similar trends for the effect of treatments on flower formation of 'Honeycrisp' were observed in 2013 and 2014, despite the difference in overall flower formation between the years. $\mathrm{GA}_{4+7}$ application significantly inhibited flower formation in both years, but defoliation significantly inhibited flower formation only in 2013 (Fig. 1). However, NAA applications did not affect flower formation compared with controls in either year of the experiment (Fig. 1).

EFFECT OF $\mathrm{GA}_{4+7}$ AND DEFOLIATION TREATMENTS ON MoFT1, 2 AND MDTFL1-1 TRANSCRIPT LEVELS. Defoliation

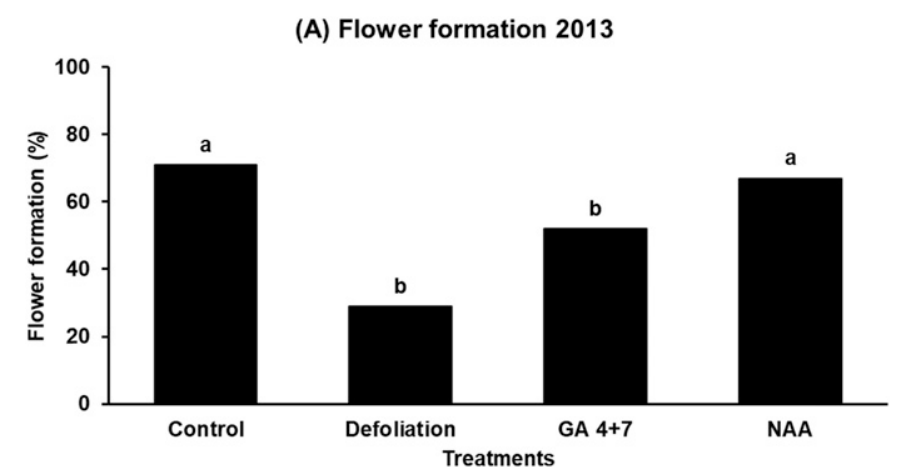

(B) Flower formation 2014

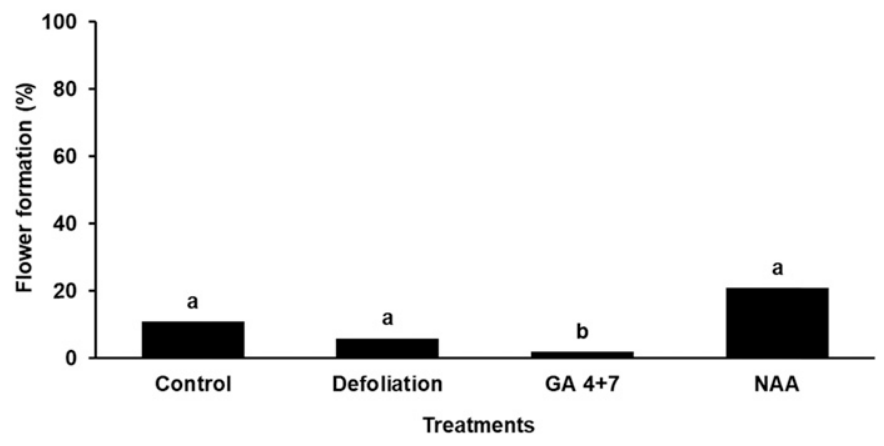

Fig. 1. Effect of defoliation and gibberellin $\left(\mathrm{GA}_{4+7}\right)$ and 1-naphthaleneacetic acid (NAA) applications on 'Honeycrisp' apple flower formation in 2013 (A) and 2014 (B). Data are presented as percentage of flower formation and were analyzed using binomial logistic regression with mixed effects. Different letters indicate significantly different values to the control $(P<0.05)$.

reduced MdFT1, 2 transcript levels both at 24 DAFB in 2013 and 49 DAFB in 2014 , whereas $\mathrm{GA}_{4+7}$ treatment only affected MdFT1 transcript levels at 49 DAFB in 2014 (Fig. 2A and E). On all other sample dates, MdFT1, 2 steady state transcript levels were unaffected by the treatments (Fig. 2B-D and F).

MdTFL1-1 transcripts were significantly downregulated by defoliation on all sample dates in 2013 and on the first two sample dates (26 and 49 DAFB) in 2014 (Fig. 3). Application of $\mathrm{GA}_{4+7}$ increased MdTFL1-1 transcript levels at 46 and 66 DAFB in 2013 and 26 DAFB in 2014 (Fig. 3B-D).

\section{Discussion}

Despite hand thinning to reduce crop loads to levels that would be considered "light" by commercial standards; flower formation in 2014 was very low (Fig. 1). This highlights the 

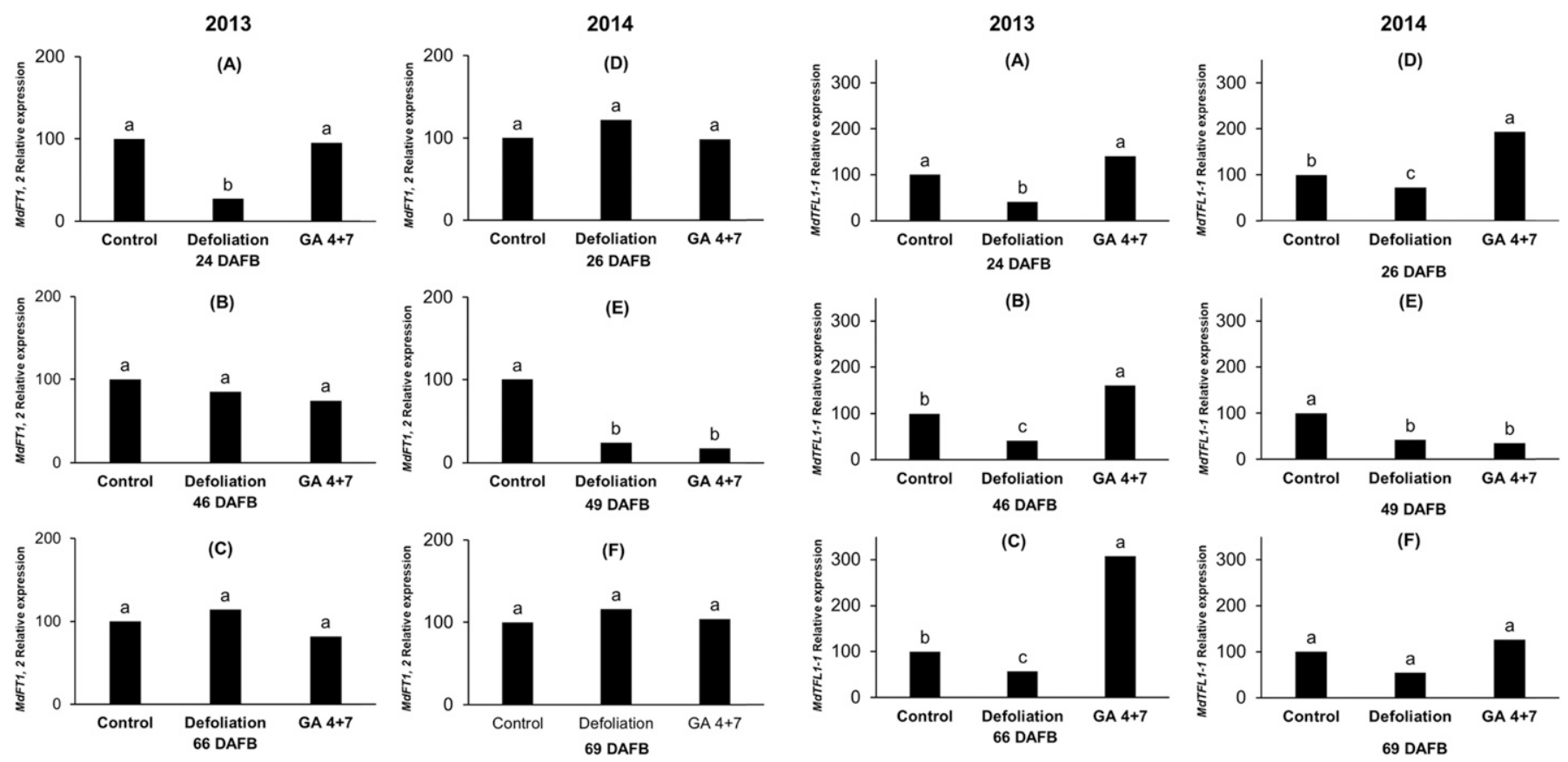

Fig. 2. Effect of defoliation and application of gibberellins $\left(\mathrm{GA}_{4+7}\right)$ to 'Honeycrisp' apple on MdFT1, 2 (MDP0000132050) and (MDP0000139278) expression patterns in 2013 at $24 \mathrm{~d}(\mathbf{A}), 46 \mathrm{~d}(\mathbf{B})$, and $66 \mathrm{~d}(\mathbf{C})$ after full bloom and in 2014 at $26 \mathrm{~d}(\mathbf{D}), 49 \mathrm{~d}(\mathbf{E})$, and $69 \mathrm{~d}(\mathbf{F})$ after full bloom (DAFB). Realtime quantitative reverse transcriptase PCR results were analyzed using the $2(-\Delta \Delta \mathrm{CT})$ method using Ubiquitin $\mathrm{C}(U B C)$ as an internal control. Statistical significance was determined using the two-tailed Student's $t$ test. Different letters indicate significantly different values to the control $(P<0.05)$.

very biennial nature of 'Honeycrisp' and may have been due to the time of thinning (petal fall), as earlier blossom thinning has been shown to be more effective at promoting return bloom than later thinning as practiced here (Tromp, 2000).

Two major flower formation inhibitors have been previously described in apple: GAs (Marino and Greene 1981; McArtney and Li, 1998; McLaughlin and Greene, 1984) and defoliation (Elsysy and Hirst 2017; Fulford, 1960; Harley et al., 1942). In most of these previous studies, treatments were applied either on whole trees or to major branches. However, in this study, we applied these two putative flowering inhibitors locally to individual spurs. We demonstrated that these inhibitors gain their effects by affecting the treated spurs, as the local exogenous $\mathrm{GA}_{4+7}$ application significantly inhibited local flower formation compared with the control in both years. Similar trends were seen for local defoliation which also inhibited local flower formation compared with the control, although this was significantly lower only in 2013 (Fig. 1). Local defoliation and $\mathrm{GA}_{4+7}$ application likely act via manipulation of the complicated molecular networks involved in the apple flowering pathway.

Flowering locus $\mathrm{T}$ is produced in leaves of many species (Mimida et al., 2013), but in apple, it is unclear whether it is produced in apical buds (Kotoda et al., 2010) or leaves (Xing et al., 2015). In this experiment, local spur defoliation reduced flower formation in 2013 compared with the control, and this reduction was accompanied by a reduction in MdFT1, 2 transcript levels early in the season (24 DAFB) (Fig. 2A). Defoliation removes the source of any potential leaf-produced
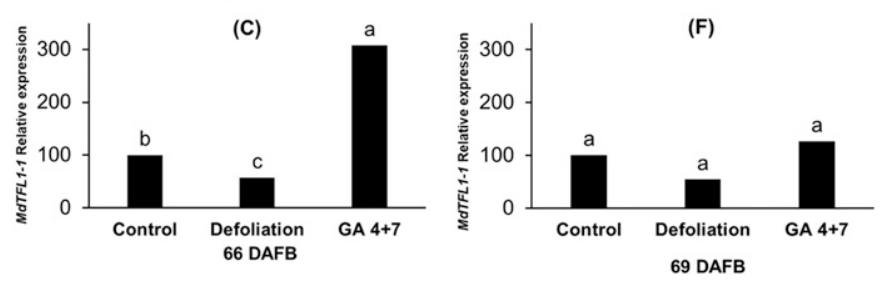

Fig. 3. Effect of defoliation and application of gibberellins $\left(\mathrm{GA}_{4+7}\right)$ to 'Honeycrisp' apple on MdTFL1-1 (MDP0000255437) expression patterns in 2013 at $24 \mathrm{~d}(\mathbf{A}), 46 \mathrm{~d}(\mathbf{B})$, and $66 \mathrm{~d}(\mathbf{C})$ after full bloom and in 2014 at $26 \mathrm{~d}$ (D), $49 \mathrm{~d}($ E) , and $69 \mathrm{~d}(\mathbf{F})$ after full bloom (DAFB). Real-time quantitative reverse transcriptase PCR results were analyzed using the $2(-\Delta \Delta \mathrm{CT})$ method using Ubiquitin $\mathrm{C}(U B C)$ as an internal control. Statistical significance was determined using the two-tailed Student's $t$ test. Different letters indicate significantly different values to the control $(P<0.05)$.

$M d F T 1,2$. Therefore, the decline in MdFT1, 2 transcript levels as a result of spur defoliation suggests that leaves are the major site of $M d F T 1,2$ production in apple, although our data suggest there may be other sources. Two observations led us to make this suggestion. First, flower formation occurred in defoliated spurs in both years, and defoliated spurs showed similar flower formation compared with the control in 2014. Second, MdFT1, 2 transcript levels were only reduced in defoliated spurs on one sample date in 2013 (24 DAFB) and one sample date in 2014 (49 DAFB). On all other sample dates, transcript levels were unaffected (Fig. 2). If $M d F T 1,2$ transcripts are necessary for flower formation, then these must have originated from other sources to be present in apical buds of defoliated spurs.

Logically, treatments that reduce flowering, such as defoliation, might be expected to increase transcripts of negative regulators of flowering, such as MdTFL1. Previously, defoliation of bourse shoot apices 49 DAFB led to a large increase (13-fold) in MdTFL1-2 $13 \mathrm{~d}$ after leaf removal (Haberman et al., 2016). However, in this study, defoliation at petal fall led to a consistent reduction in MdTFL1-1 transcripts compared with controls in almost all sample dates in both years (Fig. 3). Therefore, we suggest that local leaves may be more important for the expression of MdTFL1-1 than the expression of MdFT1, 2.

Both the crop load and GA application showed a similar positive effect on MdTFL1-2 expression level (Haberman et al., 2016). In this experiment, reduction in flower formation in response to local $\mathrm{GA}_{4+7}$ application was observed in both years and was accompanied by significant increases in MdTFL1-1 transcript levels 46 and 66 DAFB in 2013 and 24 
DAFB in 2014 (Fig. 3). On the other hand, in five of the six sample dates across both years, exogenous $\mathrm{GA}_{4+7}$ application did not affect $M d F T 1,2$ transcript levels compared with the control (Fig. 2). Hence, we suggest that exogenous $\mathrm{GA}_{4+7}$ application inhibits flowering in 'Honeycrisp' apple by promoting MdTFL1-1 expression (on two sample dates in 2013 and one sample date in 2014) and acts in addition to the role of GAs in downregulating the SOC1 transcription factor in apical buds (Xing et al., 2015).

All treatments were located on the same trees. We ensured that treated spurs were at least $20 \mathrm{~cm}$ from each other to minimize interactions among them. Although it is possible that one treatment affected another, this would seem unlikely to have played a major role in determining the results for two reasons. First, any effects would be reflected in the controls, and all results were compared with controls. Second, any distant effects would seem to be minor in comparison with the local spur treatment effect.

In conclusion, this study suggests that exogenous $\mathrm{GA}_{4+7}$ application inhibited flowering by increasing the expression levels of a negative regulator of flowering, MdTFL1-1, in apical buds 46 and 66 DAFB in 2013 and 24 DAFB in 2014 (Fig. 3). Defoliation, on the other hand, reduced the flowering promoters (MdFT1, 2) 24 DAFB in 2013 and 49 DAFB in 2014 and reduced the flowering inhibitor (MdTFL1-1) in all sample dates in 2013 and in two of three sample dates in 2014 (Figs. 2 and 3). We propose that flower-promoting signals are not localized only within the spurs but have different sources within the tree. Moreover, the leaves in the vicinity of flower buds regulate expression pattern of MdTFL1-1 more than the expression of MdFT1, 2.

\section{Literature Cited}

Bangerth, K.F. 2009. Floral induction in mature, perennial angiosperm fruit trees: Similarities and discrepancies with annual/biennial plants and the involvement of plant hormones. Scientia Hort. 122:153-163. Chan, B.G. and C. Cain. 1967. The effect of seed formation on subsequent flowering in apple. Proc. Amer. Soc. Hort. Sci. 91:63-68. Davis, L.D. 1957. Flowering and alternate bearing. Proc. Amer. Soc. Hort. Sci. 70:545-556.

Davis, D.E. 2002. Inhibition of flower bud initiation and development in apple by defoliation, gibberellic acid and crop load manipulation. Virginia Polytechnic Inst. State Univ., Blacksburg, PhD Diss.

Dennis, F.G. and J.P. Nitsch. 1966. Identification of gibberellins A4 and A7 in immature apple seeds. Nature 211:781-782.

Dennis, F.G. and J.C. Neilsen. 1999. Physiological factors affecting biennial bearing in tree fruit: The role of seeds in apple. HortTechnology 9:317-322.

Elsysy, M.A. and P.M. Hirst. 2017. The role of spur leaves, bourse leaves, and fruit on local flower formation in apple: An approach to understanding biennial bearing. HortScience 52:1229-1232.

Elsysy, M.A., M.V. Mickelbart, and P.M. Hirst. 2019. Effect of fruiting and biennial bearing potential on spur quality and leaf gas exchange in apple. J. Amer. Soc. Hort. Sci. 144:31-37.

Esumi, T., R. Tao, and K. Yonemori. 2005. Isolation of $L E A F Y$ and TERMINAL FLOWER1 homologues from six fruit tree species in the subfamily Maloideae of the Rosacea. Sex. Plant Reprod. 17:277287.

Flachowsky, H., I. Szankowski, S. Waidmann, A. Peil, C. Tränkner, and M.V. Hanke. 2012. The MdTFL1 gene of apple (Malus $\times$ domestica Borkh.) reduces vegetative growth and generation time. Tree Physiol. 32:1288-1301.

Fulford, R.M. 1960. The use of defoliating sprays for the control of biennial bearing in apples. HortScience 35:202-213.
Guitton, B., J.J. Kelner, R. Velasco, S.E. Gardiner, D. Chagneì, and E. Costes. 2012. Genetic control of biennial bearing in apple. J. Expt. Bot. 63:131-149.

Guitton, B., J.J.K. Kelner, J.M. Celton, X. Sabau, J.P. Renou, D. Chagné, and E. Costes. 2016. Analysis of transcripts differentially expressed between fruited and deflowered 'Gala' adult trees: A contribution to biennial bearing understanding in apple. BMC Plant Biol. 16:1-22.

Haberman, A., M. Ackerman, O. Crane, J.J. Kelner, E. Costes, and A. Samach. 2016. Different flowering response to various fruit loads in apple cultivars correlates with degree of transcript reaccumulation of a TFL1-encoding gene. Plant J. 87:161-173.

Hanke, M.V., H. Flachowsky, A. Peil, and C. Hättasch. 2007. No flower no fruit-Genetic potentials to trigger flowering in fruit trees. Genes Genomes Genomics 1:1-20.

Harley, C.P., J.R. Magness, M.P. Masure, L.A. Fletcher, and E.S. Degman. 1942. Investigations on the cause and control of biennial bearing of apples. U.S. Dept. Agr. Tech. Bul. 792.

Hättasch, C., H. Flachowsky, M.V. Hanke, S. Lehmann, A. Gau, and D. Kapturska. 2009. The switch to flowering: Genes involved in floral induction of the apple 'Pinova' and the role of the flowering gene MdFT. Acta Hort. 839:701-705.

Hirst, P.M. 2017. Advances in understanding flowering and pollination in apple trees, p. 85-101. In: K. Evans (ed.). Achieving sustainable cultivation of apples. Burleigh Dodds Scientific Publ., Cambridge, UK.

Hirst, P.M. and D.C. Ferree. 1995. Rootstock effects on the flowering of 'Delicious' apple. I. Bud development. J. Amer. Soc. Hort. Sci. 120:1010-1017.

Japelaghi, R.H., R. Haddad, and G.A. Garoosi. 2011. Rapid and efficient isolation of high quality nucleic acids from plant tissues rich in polyphenols and polysaccharides. Mol. Biotechnol. 49:129137.

Kotoda, N. and M. Wada. 2005. MdTFL1, a TFL1-like gene of apple, retards the transition from the vegetative to reproductive phase in transgenic Arabidopsis. Plant Sci. 168:95-104.

Kotoda, N., H. Iwanami, S. Takahashi, and K. Abe. 2006. Antisense expression of MdTFL1, a TFL1-like gene, reduces the juvenile phase in apple. J. Amer. Soc. Hort. Sci. 131:74-81.

Kotoda, N., H. Hayashi, M. Suzuki, M. Igarashi, Y. Hatsuyama, S. Kidou, T. Igasaki, M. Nishiguchi, K. Yano, T. Shimizu, S. Takahashi, H. Iwanami, S. Moriya, and K. Abe. 2010. Molecular characterization of FLOWERING LOCUS T-like genes of apple (Malus $\times$ domestica Borkh.). Plant Cell Physiol. 51:561-575.

Liewelyn, F.W.M. 1968. The effect of partial defoliation at different times in the season on fruit drop and shoot growth in Lord Lambourne apple trees. J. Hort. Sci. 43:519-526.

Livak, K.J. and T.D. Schmittgen. 2001. Analysis of relative gene expression data using real-time quantitative PCR and the 2-DDCT method. Methods 25:402-408.

Marino, F. and D.W. Greene. 1981. Involvement of gibberellins in the biennial bearing of 'Early McIntosh' apples. J. Amer. Soc. Hort. Sci. 106:593-596.

McArtney, S. and S. Li. 1998. Selective inhibition of flowering on 'Braeburn' apple trees with gibberellins. HortScience 33:699-700.

McArtney, S., D. Unrath, J.D. Obermiller, and A. Green. 2007. Naphthaleneacetic acid, ethephon, and gibberellins A4+A7 have variable effects on flesh firmness and return bloom on apple. HortTechnology 17:32-38.

McLaughlin, J.M. and D.W. Greene. 1984. Effects of BA, GA4+7 and daminozide on fruit set, fruit quality, vegetative growth, flower initiation, and flower quality of 'Golden Delicious' apple. J. Amer. Soc. Hort. Sci. 109:34-39.

Mimida, N., S. Kidou, H. Iwanami, S. Moriya, K. Abe, C. Voogd, E. Varkonyi-Gasic, and N. Kotoda. 2011. Apple FLOWERING LOCUS $\mathrm{T}$ proteins interact with transcription factors implicated in cell growth and organ development. Tree Physiol. 31:555-566. 
Mimida, N., S. Komori, A. Suzuki, and M. Wada. 2013. Functions of the apple TFL1/FT orthologs in phase transition. Scientia Hort. 156:106-112.

Pillitteri, L.J., C.J. Lovatt, and L.L. Walling. 2004. Isolation and characterization of a TERMINAL FLOWER homolog and its correlation with juvenility in citrus. Plant Physiol. 135:1540-1551.

Sahulka, J. 1967. The effect of summer defoliation on fruit bud initiation in some varieties of apple trees. Biol. Plant. 9:394-395.

Shalom, L., S. Samuels, N. Zur, L. Shlizerman, H. Zemach, M. Weissberg, R. Ophir, E. Blumwald, and A. Sadka. 2012. Alternate bearing in citrus: Changes in the expression of flowering control genes and in global gene expression in $\mathrm{ON}$ - versus OFF-crop trees. PLoS One 7(10):e46930.

Storch, T.T., C. Pegoraro, T. Finatto, V. Quecini, C.V. Rombaldi, and C. Girardi. 2015. Identification of a novel reference gene for apple transcriptional profiling under postharvest conditions. PLoS One 10(3):e0120599.

Tromp, J. 2000. Flower-bud formation in pome fruits as affected by fruit thinning. Plant Growth Regulat. 31:27-34.

Tustin, D.S., C.J. Stanley, and H.M. Adams. 1997. Physiological and phenological responses of apple trees to artificial reduction of the growth period from harvest to leaf fall. Acta Hort. 451:383392.

Untergasser, A., I. Cutcutache, T. Koressaar, J. Ye, B.C. Faircloth, M. Remm, and S.G. Rozen. 2012. Primer3-New capabilities and interfaces. Nucleic Acids Res. 40:e115.

Xing, L.B., D. Zhang, Y.M. Li, Y.W. Shen, C.P. Zhao, J.J. Ma, N. An, and M.Y. Han. 2015. Transcription profiles reveal sugar and hormone signaling pathways mediating flower induction in apple (Malus domestica Borkh.). Plant Cell Physiol. 56:2052-2068. 